\title{
The Frequency of Aspirin and Clopidogrel Resistance and Related Factors in Patients Undergoing Elective Percutaneous Coronary Intervention
}

\author{
(1) Dilay Karabulut1, (D) Ayşem Kaya², (1) Okay Abacı3, (1) Umut Karabulut4, () Fatma Nihan Turhan \\ Çağlar1, (1) Alev Arat Özkan5
}

${ }^{1}$ University of Health Sciences Turkey, Bakırköy Dr. Sadi Konuk Training and Research Hospital, Department of Cardiology, İstanbul, Turkey 2̇̇stanbul University-Cerrahpaşa, Cardiology Institute, Department of Biochemistry, İstanbul, Turkey

3̇̇stanbul University-Cerrahpaşa, Cardiology Institute, Department of Cardiology, İstanbul, Turkey

4İstanbul Acıbadem International Hospital, Clinic of Cardiology, İstanbul, Turkey

${ }^{5}$ Koç University Faculty of Medicine, Department of Cardiology, İstanbul, Turkey

\begin{abstract}
Objectives: Dual antiplatelet therapy with aspirin and a P2Y12 inhibitor is the mainstay of antithrombotic therapy after myocardial infarction and percutaneous coronary interventions (PCI). Despite chronic oral antiplatelet therapy, many atherothrombotic events continue to occur. Several reports in the literature have shown possible relationships between residual platelet activity and clinical outcomes, raising the possibility that "resistance" to oral antiplatelet therapy may underlie such adverse events. In this study, we aimed to determine the prevalence of aspirin and clopidogrel resistance, and related factors. We also aimed to identify the predictors of reduced antiplatelet response among patients undergoing elective PCI for stable coronary artery disease (CAD).

Materials and Methods: We retrospectively included patients who underwent an elective PCI with available aggregation inhibition test results. According to aggregation inhibition test results, patients were divided into two
\end{abstract}

Address for Correspondence: Umut Karabulut, İstanbul Acıbadem International Hospital, Clinic of Cardiology, İstanbul, Turkey e-mail: umkarabulut@gmail.com ORCID: orcid.org/0000-0002-3947-9173

Received: 10.02.2021 Accepted: 26.04.2021

Cite this article as: Karabulut D, Kaya A, Abacı O, Karabulut U, Turhan Çağlar FN, Arat Özkan A. The Frequency of Aspirin and Clopidogrel Resistance and Related Factors in Patients Undergoing Elective Percutaneous Coronary Intervention.

EJCM 2021;9(2):94-104.

DOI: 10.32596/ejcm.galenos.2021-02-012

${ }^{\circ}$ Copyright 2021 by Heart and Health Foundation of Turkey (TÜSAV) / E Journal of Cardiovascular Medicine published by Galenos Publishing House. 
subgroups: 1-aspirin resistant/low responders and responders 2-clopidogrel resistant/low responders and responders.

Results: Totally 470 patients with aggregation inhibition test results (all 470 for clopidogrel and 464 for aspirin) were included in the study. Three hundred sixty-eight of them were male (78, 3\%). The aspirin resistance group's mean age was $60.8 \pm 10.3$ years, the clopidogrel resistance group's mean age was $58.89 \pm 10.1$ years, and the aspirin + clopidogrel resistance group's age was $63.25 \pm 8.8$ years. Overall, there were 164 patients with single (either aspirin or clopidogrel) and $16(3 \%)$ patients with double resistance. Hypertension, statin use, and platelet count were found as independent predictors of aspirin resistance. Hyperlipidemia, gender, and leucocyte count were found as independent predictors of clopidogrel resistance.

Conclusion: $8.1 \%$ and $26.8 \%$ of stable CAD patients undergoing elective PCI showed insufficient aggregation inhibition by aspirin and clopidogrel, respectively, whereas 3\% had double resistance.

Keywords: Aspirin, clopidogrel, resistance, percutaneous coronary intervention

\section{Introduction}

Cardiovascular diseases are the number one cause of mortality and morbidity globally ${ }^{(1)}$. The majority of cardiovascular diseases and their complications are of atherosclerotic origin ${ }^{(2)}$. Platelets play a major role in atherosclerotic cardiovascular disease; thus, antiplatelet therapy is the key component in treating and preventing acute and chronic coronary syndromes. Dual antiplatelet therapy (DAPT) with aspirin and a P2Y12 inhibitor is the mainstay of antithrombotic therapy after myocardial infarction (MI) and percutaneous coronary interventions (PCI). Antithrombotic effects of aspirin have been known for more than fifty years ${ }^{(3-6)}$. Aspirin decreases platelet aggregation by irreversibly blocking cyclooxygenase- 1 mediated thromboxane A2 syntheses, a potent platelet aggregation mediator and vasoconstrictor agent ${ }^{(7)}$. P2Y12 receptor, the target of P2Y12 inhibitors, plays a key role in platelet activation and the amplification of arterial thrombus formation. The first P2Y12 inhibitor, clopidogrel, was the standard for DAPT until the newer molecules became available ${ }^{(8)}$. The newer P2Y12 inhibitors ticagrelor and prasugrel, with their fast onset action and potent antiplatelet effects and proven superiority regarding MACE (major adverse cardiac event), got a higher class of recommendation over clopidogrel in acute coronary syndrome (ACS) guidelines leaving room for the use of the latter only in patients who cannot receive or have contraindications for the others and in those receiving thrombolysis ${ }^{(9-11)}$. On the contrary, in stable coronary artery disease (CAD) patients undergoing PCI, DAPT consisting of clopidogrel and aspirin still has a class IA indication and is used in many patients ${ }^{(11)}$. As there are no randomized controlled trials investigating the use of ticagrelor or prasugrel instead of clopidogrel in stable CAD patients undergoing PCI, these agents can only be used in selected patients, e.g., in those with unsatisfactory clinical results when using clopidogrel ${ }^{(11)}$. In patients with atrial fibrillation, who undergo PCI, clopidogrel is the P2Y12 inhibitor of the triple therapy as the safety and efficacy data from randomized controlled trials (RCTs) for prasugrel and ticagrelor lack and as there are worrisome bleeding signals in registries ${ }^{(12,13)}$.

Still being used in a large number of patients, as mentioned above, clopidogrel's disadvantage is its potentially variable efficacy. Despite chronic oral antiplatelet therapy, a number of atherothrombotic events continue to occur. Several reports in the literature have shown possible relationships between residual platelet activity, as measured with a variety of laboratory tests, and clinical outcomes, raising the possibility that 
"resistance" to oral antiplatelet therapy may underlie such adverse events ${ }^{(14)}$. Many studies have reported antiplatelet treatment responses, but because various methods have been used in different patients, no consistent estimates of the prevalence of antiplatelet treatment resistance or its clinically significant predictors have been produced. In this study, we investigated the prevalence of aspirin and clopidogrel resistance, related factors, and the predictors of reduced antiplatelet response among patients undergoing elective PCI for stable CAD.

\section{Materials and Methods}

We retrospectively screened the patient data from January 2007 to 2009 May, as during that period, all PCI patients had a routine aggregation inhibition test 24 hours after the intervention (48 hours after the loading dose), and the treating doctor made dose/medication changes according to test results. All patients who underwent an elective PCI with an available aggregation inhibition test result were included in the study.

Resistance (hypo or non-responsiveness) is defined as "High on-treatment platelet reactivity," whereas the occurrence of a thrombotic event during therapy is defined as treatment failure ${ }^{(15)}$.

Exclusion criteria: Patients on chronic DAPT, scheduled for elective PCI after an ACS, patients with hematologic and oncologic disorders, collagen disease, active infection, and chronic liver disease were not included.

Demographic data, risk factors [diabetes mellitus (DM), hypertension (HT), family history, hyperlipidemia (HL), smoking status], other comorbidities, medications [aspirin, beta-blockers, angiotensin-converting enzyme inhibitor/angiotensin receptor blocker (ACE-I/ARB), calcium channel blockers, proton pump inhibitors (PPI)] and laboratory findings, as well as indications for intervention, were recorded from patient files. Aggregation inhibition test results at post PCI $24^{\text {th }}$ hour, treatment changes, and the results of control aggregation inhibition test (if any) were also recorded. According to aggregation inhibition test results, patients were analyzed in two subgroups: 1-aspirin resistant/low responders and responders 2-clopidogrel resistant/low responders and responders.

Loading dose: In our clinic, patients routinely received $300 \mathrm{mg}$ clopidogrel one day prior to the elective procedure and $1 \times 75 \mathrm{mg}$ per day afterward.

Resistance: The expected on-treatment ranges were 0-300 AU for Aspirin and 0-200 AU for clopidogrel. The patients with higher levels were classified as "resistant patients" (insufficient aggregation inhibition), and other patients were classified as "normal responders," and these two groups were compared in terms of clinical and biochemical features.

Aggregation inhibition test: Aggregation inhibition by aspirin and clopidogrel was analyzed from venous blood samples obtained from antecubital vein 24 hours after the intervention (48 hours after the loading dose) by impedance aggregometry method using on the Multiplate Analyzer (Roche, Switzerland). Multiple electrode aggregometry (MEA) is a method that tests platelet function in whole blood based on whole blood impedance aggregometry. The Multiplate ${ }^{\circledR}$ has five testing areas that can be loaded with the MEA test cells, each of the test cells has two independent sensor units, which are made of two silver-coated, highly conductive copper wires. The multiplate works by measuring platelet adhesion and aggregation to these conductive wires following activation of the platelets. As aggregation increases, there is an increase in electrical impedance between the wires, which is recorded on the Multiplate ${ }^{\circledR}$ device ${ }^{(16)}$. Platelet aggregation determined by MEA is calculated from the area under the curve (AUC), which is taken from the measured electrical impedance and quantified by arbitrary aggregation units over time (AU*min). Prostaglandin E1 (PGE1) is a natural platelet inhibitor that triggers an increase in cAMP levels in the platelet. The cAMP is a so-called second messenger, i.e., an intracellular signaling 
molecule. A decrease in the cAMP level in the platelet leads to platelet activation. An increase of the cAMP level counteracts platelet activation. PGE1 reagent is used in combination with adenosine diphosphate (ADP) test reagent. The addition of $20 \mu \mathrm{L}$ PGE1 to the ADP test (9.4 nM PGE1 final concentration) induces a moderate inhibition of platelet activation in normal blood samples, but a significant increase of sensitivity of the ADP test to platelet inhibition by substances that affect platelet aggregation through ADP receptor binding is seen. Therefore, this modified test is named high-sensitive ADP test $^{(17)}$.

Platelet inhibition by aspirin is monitored using arachidonic acid-induced aggregometry. ADP triggers platelet activation via platelet ADP receptors. In addition, a second test is performed with the addition of PGE1, a physiological platelet inhibitor. PGE1 reduces the intracellular mobilization of calcium in platelets and thus acts synergistically to the action of clopidogrel. The use of PGE1 increased the sensitivity of the test $\mathrm{t}^{(16)}$.

This study was approved by the Ethics Committee of Bakırköy Dr. Sadi Konuk Training and Research Hospital (decision no: 2021-296, date:17/05/2021).

\section{Statistical Analysis}

The arithmetic mean of the data was calculated for the demographic features of the patient, and the standard deviation was calculated through the chi-square test, Mann-Whitney U test, or Fisher's exact test (mean \pm standard deviation). The distribution of categorical variables was evaluated by each other. The mean of the features having any of two subtitles in terms of quantitative variables was compared with the t-test for independent groups (independent samples t-test). The correlation of two quantitative features was analyzed with the Pearson correlation coefficient. The binary logistic regression model was used as a multivariable statistical method, in which the result variable was categorized as existing/not existing. The level of significance was accepted as $p \leq 0.05$ in all analyses. SPSS for the windows 15.0 statistics package was used for the evaluation of the data.

\section{Results}

Totally 470 patients with aggregation inhibition test results (all 470 for clopidogrel and 464 for aspirin) were included in the study. Three hundred sixty-eight of them were male $(\mathrm{n}=78,3 \%)$. The aspirin resistance group's mean age was $60.8 \pm 10.3$ years, the clopidogrel resistance group's mean age was $58.89 \pm 10.1$ years, and the aspirin + clopidogrel resistance group's mean age was $63.25 \pm 8.8$ years. Overall, there were 164 patients with single (either aspirin or clopidogrel) and $16(3 \%)$ patients with double resistance (both aspirin and clopidogrel).

Aspirin resistance: There were 38 patients $(8,1 \%)$ with aspirin resistance. HT and HL were significantly more frequent among resistant patients, as oral antidiabetic (OAD), statin, beta-blocker, and ACE-I use. In contrast, the smoking rate was higher among normal responders (Table 1). Logistic regression analysis revealed that HT, statin use, and platelet count were independent predictors of aspirin resistance (Table 2). Aspirin resistant patients had significantly higher levels of blood urea, low density lipoprotein (LDL), CRP, and platelets. A negative correlation was detected between aspirin aggregation levels and fasting blood glucose, while C-reactive protein (CRP), leukocyte count, and platelet count had a positive correlation (Table 3).

Clopidogrel resistance: There were 126 patients (26.8\%) with clopidogrel resistance. Female gender, DM, HL, and family history for ischemic heart disease were significantly more frequent among clopidogrel resistant patients, whereas the smoking rate was higher among normal responders. Body mass index (BMI), waist circumference, leucocyte count, and hemoglobulin levels were significantly higher among clopidogrel resistant groups as well as nitrate and statin use (Table 4). Independent predictors of clopidogrel resistance (CR) were HL, gender, and leucocyte count (Table 5). 
Table 1. Demographic and biochemical features of the groups with and without aspirin resistance

\begin{tabular}{|c|c|c|c|}
\hline Aspirin & $\begin{array}{l}\text { ASA (-) } \\
(n=426)\end{array}$ & $\begin{array}{l}\text { ASA (+) } \\
(n=38)\end{array}$ & p-value \\
\hline Age & $59.5 \pm 10.2$ & $60.8 \pm 10.3$ & 0.42 \\
\hline Gender (female) (\%) & $90(21.1)$ & $12(31.6)$ & 0.13 \\
\hline Hypertension (\%) & $214(50.7)$ & $28(73.7)$ & $0.007^{*}$ \\
\hline Diabetes mellitus (\%) & $114(27)$ & $12(31.6)$ & 0.54 \\
\hline Hyperlipidemia (\%) & $144(34)$ & $22(57.9)$ & $0.003^{*}$ \\
\hline Smoking (\%) & $228(54)$ & $14(36.8)$ & $0.04^{*}$ \\
\hline BMI (weight/height ${ }^{2}$ ) & $28.03 \pm 3.5$ & $29.7 \pm 13.5$ & 0.49 \\
\hline Waist circumference $(\mathrm{cm})$ & $97.9 \pm 11.1$ & $99.2 \pm 15.3$ & 0.54 \\
\hline Family history (\%) & $126(29.6)$ & $12(31.6)$ & 0.79 \\
\hline Fasting glucose (mg/dL) & $117.8 \pm 37.0$ & $108.2 \pm 30.4$ & 0.14 \\
\hline Urea (mg/dL) & $17.1 \pm 5.8$ & $19.5 \pm 6.7$ & $0.03^{*}$ \\
\hline Creatine (mg/dL) & $0.9 \pm 0.1$ & $0.9 \pm 0.2$ & 0.26 \\
\hline LDL (mg/dL) & $120.2 \pm 32.9$ & $135 . \pm 57.1$ & $0.01^{*}$ \\
\hline HDL (mg/dL) & $43.1 \pm 9.1$ & $44.4 \pm 7.8$ & 0.40 \\
\hline Platelet (10e3/uL) & $216912.6 \pm 58413.1$ & $244,823.5 \pm 58,915.6$ & $0.008^{*}$ \\
\hline Leucocyte (10e3/uL) & $8,255.7 \pm 6,192.3$ & $7,467.6 \pm 1,953.7$ & 0.46 \\
\hline eGFR (mL/dk) & $83.1 \pm 16.2$ & $84.4 \pm 24.2$ & 0.77 \\
\hline CRP (mg/L) & $4.2 \pm 2.4$ & $21.7 \pm 20.8$ & $<0.001^{*}$ \\
\hline Hemoglobin (g/dL) & $13.3 \pm 1.4$ & $13.0 \pm 2.0$ & 0.21 \\
\hline Insulin (\%) & $59(13.9)$ & $4(10.5)$ & 0.56 \\
\hline OAD (\%) & $77(18.1)$ & $10(26.3)$ & 0.21 \\
\hline ССВ (\%) & $65(15.3)$ & $6(15.8)$ & 0.93 \\
\hline Nitrate use (\%) & $133(31.2)$ & $14(36.8)$ & 0.47 \\
\hline Statin use (\%) & $138(32.4)$ & $18(47.4)$ & 0.06 \\
\hline Beta blocker (\%) & $150(35.2)$ & $23(60.5)$ & $0.002^{*}$ \\
\hline ACE-i (\%) & $129(30.3)$ & $18(47.4)$ & $0.03^{*}$ \\
\hline ARB (\%) & $67(15.7)$ & $6(15.8)$ & 0.99 \\
\hline PPI (\%) & $85(20.0)$ & $6(15.8)$ & 0.53 \\
\hline
\end{tabular}

ASA: Acetylsalicylic acid, BMI: Body mass index, LDL: Low density lipoprotein, HDL: High density lipoprotein, eGFR: Estimated glomerular filtration rate, CRP: C-reactive protein, PDW: Platelet distribution width, OAD: Oral antidiabetic, CCB: Calcium channel blocker, ACE-i: Angiotensin converting enzyme inhibitor, ARB: Angiotensin receptor blockers, PPI: Proton pump inhibitor, ${ }^{*} p<0.05$ statistically significant

A positive correlation was found between clopidogrel aggregation level and CRP, leukocyte count, and platelet count (Table 6).

\section{Discussion}

This retrospective analysis is the first study evaluating the prevalence of antithrombotic drug resistance in patients undergoing elective PCI. We found that $8.1 \%$ and $26.8 \%$ of stable CAD patients undergoing elective PCI showed insufficient aggregation inhibition by aspirin and clopidogrel, respectively, whereas 3\% had double resistance.

The difference in the measurement method we used in this study is the most important feature distinguished from other studies. In current practice, many tests are available to monitor antiplatelet therapies for patients with 
Table 2. Multivariable analyses of aspirin resistance with logistic regression

\begin{tabular}{|l|l|l|l|}
\hline & p-value & OR & $95 \% \mathbf{C I}$ \\
\hline Hypertension & $0.02^{*}$ & 2.8 & $1.1-7.1$ \\
\hline Smoking & 0.16 & 0.5 & $0.2-1.2$ \\
\hline Platelet & $0.02^{*}$ & 1.4 & $1.3-1.8$ \\
\hline eGFR & 0.49 & 1.0 & $0.9-1.0$ \\
\hline Statin & 0.06 & 2.1 & $0.9-4.7$ \\
\hline BMI & 0.48 & 0.9 & $0.8-1$ \\
\hline Diabetes mellitus & 0.66 & 0.8 & $0.3-2$ \\
\hline
\end{tabular}

eGFR: Estimated glomerular filtration rate, BMI: Body mass index, ${ }^{*} p<0.05$ statistically significant, OR: Odds ratio, Cl: Confidence interval

Table 3. Correlation coefficients and p-values of aspirin aggregation level and clinical and biochemical parameters

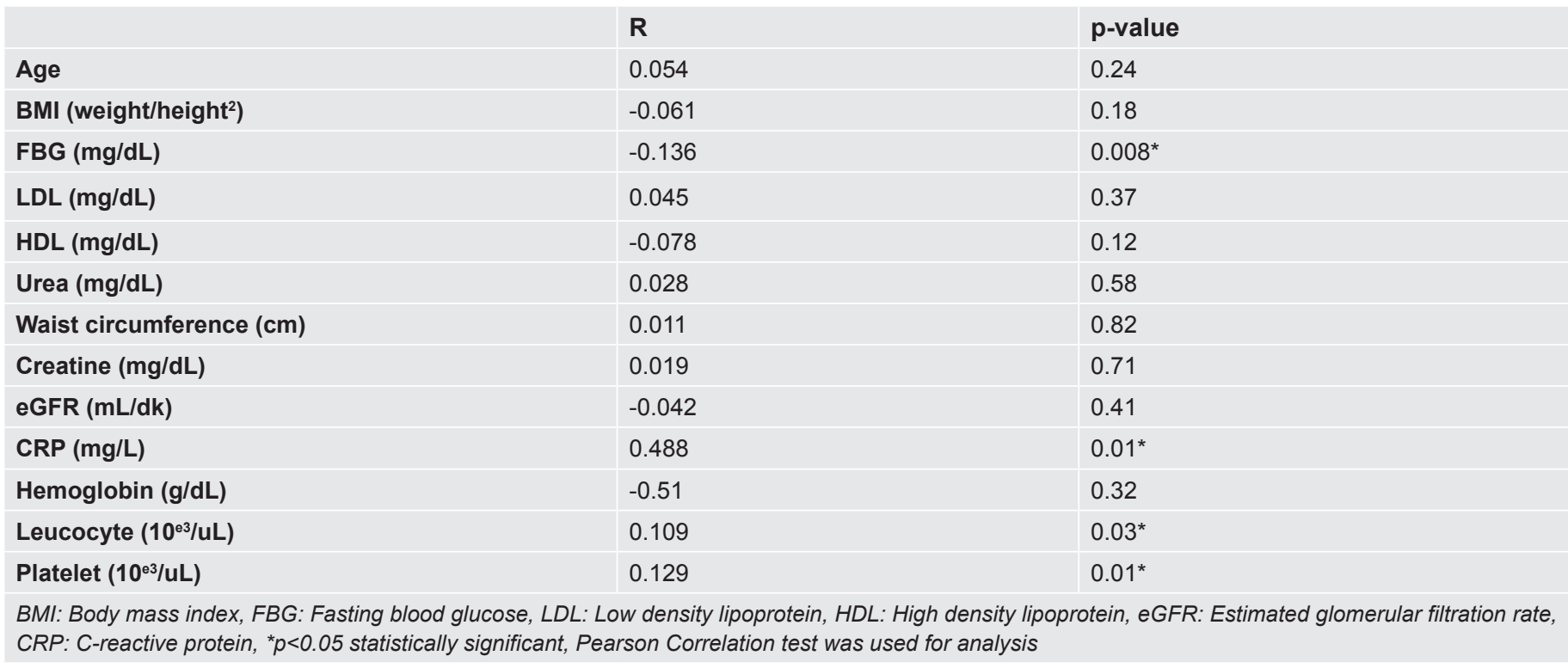

high risk. None of the currently available platelet function assays has been sufficiently validated and standardized to monitor antiplatelet therapies. In this study, the impedance aggregometry method was used to measure aspirin and clopidogrel resistance. Platelet inhibition by aspirin is monitored using arachidonic acid-induced aggregometry. Clopidogrel is detected by its inhibition of ADP-induced aggregation. Besides, a second test is performed with the addition of PGE1 and thus acts synergistically to the action of clopidogrel. Therefore, the use of PGE1 increased the sensitivity of the test ${ }^{(16,17)}$.
Literature shows that the prevalence of aspirin resistance (AR) varies between $5 \%$ and $60 \%$, while $\mathrm{CR}$ has been estimated to be between $16 \%$ and $50 \%$ depending on the population, dosing, time-point of assessment, and the method used for testing aggregation levels ${ }^{(15,18-20)}$.

Overall, our findings are consistent with the previous reports. Our study included stable CAD patients undergoing elective PCI and assessed aggregation inhibition levels 48 hours after clopidogrel loading (24 hours after PCI). Aspirin and clopidogrel resistance was presented in $8.1 \%$ and $26.8 \%$, respectively. In a similar 
Table 4. Demographic and biochemical features of the groups with and without clopidogrel resistance

\begin{tabular}{|c|c|c|c|}
\hline Clopidogrel & $\begin{array}{l}\text { Klop (-) } \\
(n=344)\end{array}$ & $\begin{array}{l}\text { Klop (+) } \\
(n=126)\end{array}$ & p-value \\
\hline Age & $59.68 \pm 10.38$ & $58.89 \pm 10.17$ & 0.46 \\
\hline Gender (female)\% & $56(16.3)$ & $46(36.5)$ & $0.001^{*}$ \\
\hline Hypertension (\%) & $172(50.3)$ & $72(58.1)$ & 0.13 \\
\hline Diabetes mellitus (\%) & $80(23.4)$ & $46(37.1)$ & $0.003^{*}$ \\
\hline Hyperlipidemia (\%) & $98(28.7)$ & $68(54.0)$ & $0.001^{*}$ \\
\hline Smoking (\%) & $194(56.7)$ & $54(43.5)$ & $0.012^{*}$ \\
\hline BMI (weight/height ${ }^{2}$ ) & $27.7 \pm 3.6$ & $29.1 \pm 7$ & $0.01^{*}$ \\
\hline Waist circumference $(\mathrm{cm})$ & $97.1 \pm 11.0$ & $99.9 \pm 12.2$ & $0.029^{*}$ \\
\hline Family history (\%) & $92(26.7)$ & $48(38.1)$ & $0.017^{*}$ \\
\hline Fasting glucose & $117.3 \pm 37.1$ & $115.6 \pm 34.7$ & 0.67 \\
\hline Urea (mg/dL) & $17.6 \pm 6.2$ & $16.5 \pm 5.2$ & 0.08 \\
\hline Creatine (mg/dL) & $0.9 \pm 0.1$ & $0.8 \pm 0.1$ & 0.13 \\
\hline LDL (mg/dL) & $120.5 \pm 37.0$ & $123.7 \pm 33.0$ & 0.42 \\
\hline HDL (mg/dL) & $43.5 \pm 9.2$ & $42.5 \pm 8.5$ & 0.28 \\
\hline Platelet count (10e3/uL) & $217,311.1 \pm 56,949.9$ & $221,996.6 \pm 63,025.1$ & 0.47 \\
\hline Leucocyte count (10 $\left.10^{\mathrm{e}} / \mathrm{uL}\right)$ & $7,927.0 \pm 6,072.3$ & $8,761.0 \pm 5,460.0$ & 0.20 \\
\hline eGFR (mL/dk) & $84.2 \pm 17.3$ & $81.5 \pm 16.1$ & 0.16 \\
\hline CRP (mg/L) & $8.6 \pm 13.2$ & $6.6 \pm 4.8$ & 0.60 \\
\hline Hemoglobin (g/dL) & $13.46 \pm 1.39$ & $13.12 \pm 1.63$ & $0.03^{*}$ \\
\hline Aspirin resistance (\%) & $24(7.1)$ & $14(11.3)$ & 0.14 \\
\hline Insulin (\%) & $55(16.0)$ & $10(7.9)$ & $0.02^{*}$ \\
\hline OAD (\%) & $70(20.3)$ & $19(15.1)$ & 0.19 \\
\hline ССВ (\%) & $55(16.0)$ & $18(14.3)$ & 0.65 \\
\hline Nitrate use (\%) & $91(26.5)$ & $58(46.0)$ & $<0.001^{*}$ \\
\hline Statin use (\%) & $98(28.5)$ & $60(47.6)$ & $<0.001^{*}$ \\
\hline Beta blocker (\%) & $121(35.2)$ & $56(44.4)$ & 0.06 \\
\hline ACE-i (\%) & $101(29.4)$ & $48(38.1)$ & 0.07 \\
\hline ARB (\%) & $53(15.4)$ & $22(17.5)$ & 0.59 \\
\hline PPI (\%) & $73(21.2)$ & $20(15.9)$ & 0.19 \\
\hline
\end{tabular}

BMI: Body mass index, LDL: Low density lipoprotein, HDL: High density lipoprotein, eGFR: Estimated glomerular filtration rate, CRP: C-reactive protein, PDW: Platelet distribution width, OAD: Oral antidiabetic, CCB: Calcium channel blocker, ACE-i: Angiotensin converting enzyme inhibitor, ARB: Angiotensin receptor blockers, PPI: Proton pump inhibitor, ${ }^{*} p<0.05$ statistically significant

but smaller series, including 151 patients taking aspirin for at least one week and clopidogrel $300 \mathrm{mg}$ loading 12 to 24 hours prior to elective PCI using a modified platelet aggregometry device, $19 \%$ of patients were found to be aspirin resistant ${ }^{(21)}$. In another study using the same loading dose as in our study, Gurbel et al. ${ }^{(22)}$ reported that
$1 / 3^{\text {rd }}$ of the patients was clopidogrel resistant at day 5 poststenting by measuring ADP-induced platelet aggregation. They also showed the clopidogrel response variability by serial measurements and a resistance rate of $15 \%$ on day 30. 
Table 5. Multivariable analyses of clopidogrel resistance with logistic regression

\begin{tabular}{|l|l|l|l|}
\hline & $\mathbf{p}$-value & OR & $\mathbf{9 5 \%} \mathbf{C I}$ \\
\hline Diabetes mellitus & 0.06 & 1.6 & $0.9-2.8$ \\
\hline BMI & 0.17 & 1.0 & $0.9-1.1$ \\
\hline Smoking & 0.34 & 0.7 & $0.4-1.3$ \\
\hline Hyperlipidemia & $0.001^{*}$ & 2.9 & $1.8-4.7$ \\
\hline Leucocyte count & $0.01^{*}$ & 1.3 & $1.1-1.6$ \\
\hline Urea & 0.04 & 0.9 & $0.91-0.99$ \\
\hline Gender & $0.03^{*}$ & 0.5 & $0.2-0.9$ \\
\hline
\end{tabular}

BMI: Body mass index, ${ }^{*} p<0.05$ statistically significant, OR: Odds ratio, Cl: Confidence interval

Table 6. Correlation between clopidogrel level and clinical and biochemical parameters

\begin{tabular}{|l|l|l|}
\hline & $\mathbf{R}$ & p-value \\
\hline Age & -0.07 & 0.13 \\
\hline BMI (weight/height') & 0.012 & 0.78 \\
\hline FBG (mg/dL) & -0.34 & $0.49^{*}$ \\
\hline LDL (mg/dL) & 0.046 & 0.36 \\
\hline HDL (mg/dL) & -0.07 & 0.14 \\
\hline Urea (mg/dL) & -0.098 & 0.06 \\
\hline Waist circumference (cm) & 0.056 & 0.26 \\
\hline Creatine (mg/dL) & -0.020 & 0.70 \\
\hline eGFR (mL/dk) & -0.006 & 0.90 \\
\hline CRP (mg/L) & 0.386 & $0.04^{*}$ \\
\hline Hemoglobin (g/dL) & 0.019 & 0.70 \\
\hline Leucocyte count (10*3/uL) & 0.171 & $0.001^{*}$ \\
\hline Platelet count (10*3/uL) & 0.115 & $0.024^{*}$ \\
\hline
\end{tabular}

BMI: Body mass index, FBG: Fasting blood glucose, LDL: Low density lipoprotein, HDL: High density lipoprotein, eGFR: Estimated glomerular filtration rate, $C R P$ : C-reactive protein, ${ }^{*} p<0.05$ statistically significant

\section{Factors Contributing to Antithrombotic Drug}

\section{Resistance}

Aspirin: Suggested causes for AR are genetic variability, non-adherence, use of enteric-coated forms, concomitant use of PPI's, body weight (under-dosing), NSAID's, and advanced atherosclerosis. There is a variety of contributing factors reported to be associated with resistance. In univariate analysis, we found a higher prevalence of HT, HL, ACE-I, beta-blocker use, and higher LDL and platelet count among aspirin resistant patients. However, only HT and platelet count were independent predictors of aspirin resistance.
The effect of gender on AR is controversial. Clinical studies reveal that $\mathrm{AR}$ is detected more in women (especially postmenopausal, over the age of 60), which is related to the low hemoglobin level ${ }^{(23,24)}$. In our study, no difference was detected between the genders. In a study by Helgason et al. ${ }^{(25)}$, a statistically significant relationship was not found between smoking and aspirin resistance, and they attributed this result to smoking-inducing platelet activation. The data of Hung et al. ${ }^{(26)}$ was also similar. However, Gum et al. ${ }^{(24)}$ reported significantly higher AR among nonsmokers. In our study, the smoking rate was higher among normal responders. Likewise, Matetzky et 
al. ${ }^{(27)}$ also found out that the response to clopidogrel in smokers was better.

Hyperglycemia is known to cause platelet reactivation and increase thrombogenicity. Furman et al. ${ }^{(28)}$ found no statistically significant difference in aspirin resistance in diabetic and non-diabetic subgroups of the patients with stable angina pectoris. We revealed similar results in this study.

Hypercholesterolemia causes aspirin resistance by increasing platelet aggregation and TXA2 level. Friend et al. ${ }^{(29)}$ demonstrated that platelets' response to aspirin was decreased in hyperlipidemic patients. Likewise, our study showed that HL was more frequent among AR patients, and in multivariate analysis, statin use had a tendency to borderline significance as an independent predictor of AR. Whether this is an indirect projection of $\mathrm{HL}$ or attributable to the direct effects of statins needs to be further evaluated. In multivariate analysis, only HT and platelet were detected as independent predictors for AR. Data on predictors of AR are sparse. In a study including stable CAD patients, fibrinogen levels and pulse pressure were reported to be independent predictors of resistance on chronic aspirin use ${ }^{(30)}$.

This study found a negative correlation between aspirin aggregation levels and fasting blood glucose, while CRP, leukocyte count, and platelet count had a positive correlation. Based on these results, we think patients with poor glycemic regulation may require strict monitoring of blood glucose to increase the effectiveness of aspirin. However, the same caution may also be required in patients with autoimmune inflammatory diseases with acute attacks.

Clopidogrel: Clopidogrel resistance or response variability is attributed mainly to the variability of genetic polymorphisms influencing absorption and isoenzyme activity, laboratory method, and drug-drug interactions $^{(31,32)}$.

The drug interactions that may change cytochrome p-450 isoenzymes in the liver may decrease the efficiency of clopidogrel. The most important ones among these drugs are statins ${ }^{(33)}$. In our study, while the use of statin was found out to be significantly high in the clopidogrel resistant group, it was not found as an independent predictor of CR in the logistic regression test.

The association of PPI use and insufficient response to clopidogrel was an issue of controversy. There is not enough evidence for a valid association between PPI induced low response and clinical adverse events, although some small studies show higher CR among PPI users ${ }^{(34)}$. In their study, Juurlink et al. ${ }^{(35)}$ demonstrated that the dual use of clopidogrel and PPI after AMI increased the risk of re-infarction by decreasing the clopidogrel efficiency; and only pantoprazole did not inhibit the cytochrome p-450 enzyme. Arbel et al. ${ }^{(34)}$ showed that omeprazole was significantly associated with more clopidogrel resistance compared to pantoprazole and famotidine. We found no association between CR and PPI use.

Likewise to PPI use, CCB and ACE-I use were also not associated with $\mathrm{CR}$ although Gurbel et al. ${ }^{(36)}$ reported that high doses of $\mathrm{CCB}$ and ACE inhibitors possibly contributed to a decreased response to clopidogrel.

Demographic variables such as age, BMI, diabetes, and renal failure may also influence clopidogrel response, either directly influencing platelet function or drug metabolism $^{(37)}$. We found no association with age. In a study conducted by Feher et al. ${ }^{(38)}$, clopidogrel resistance was found to be significantly low in patients with a low BMI. In our study, BMI and waist circumference were significantly higher in the $\mathrm{CR}$ group. In vitro studies revealed that insulin decreased platelet aggregation by P2Y12 path inhibition. However, since the sensitivity of platelet to insulin decreases in Type 2 DM patients, P2Y12 inhibition decreases ${ }^{(39)}$. In our study, clopidogrel resistance was found to be statistically higher in a patient with DM, but in multivariate analysis, diabetes was not a predictor for the CR; however, HL [odds ratio (OR): 2.9], leukocyte count (OR: 1.3), and gender (OR: 0.5) were independent predictors of CR.

\section{Study Limitations}

As a retrospective analysis, our study has some limitations. It has been reported that the level of platelet 
reactivity after a standard dose is related to the pretreatment reactivity level. As we did not routinely perform a baseline aggregation assessment, we did not have the baseline platelet reactivity levels. The lower $(300 \mathrm{mg})$ loading dose of clopidogrel used during the screened period may seem like a limitation, but all the comparators were assessing the effects of CR using the same loading dose, and it is well known that clopidogrel reaches its effective plasma level 24-48 hours after a $300 \mathrm{mg}$ loading dose. And lastly, resistance or non-responsiveness to antithrombotics is a laboratory phenomenon, and we did not assess the clinical consequences (e.g., stent thrombosis) of insufficient aggregation inhibition as this was beyond the scope of this study.

\section{Conclusion}

In conclusion, we found $8.1 \%$ and $26.8 \%$ of stable CAD patients undergoing elective PCI showed that insufficient aggregation inhibition by aspirin and clopidogrel, respectively, whereas $3 \%$ had double resistance. There is insufficient evidence for routine screening for aspirin and clopidogrel resistance in the clinical practice; however, platelet function testing may be considered in determining dual antiplatelet strategy in patients with a history of stent thrombosis and in patients prior to undergoing high-risk PCI.

\section{Ethics}

Ethics Committee Approval: This study was approved by the Ethics Committee of Bakırköy Dr. Sadi Konuk Training and Research Hospital (decision no: 2021-296, date:17/05/2021).

Informed Consent: Consent of patients were obtained.

Peer-review: Externally peer-reviewed.

\section{Authorship Contributions}

Surgical and Medical Practices: D.K., A.A.Ö., Concept: D.K., Design: F.N.T.Ç., Data Collection or Processing: A.K., Analysis or Interpretation: O.A., Literature Search: U.K., Writing: D.K., U.K.
Conflict of Interest: All the authors declare that there is no conflict of interest.

Financial Disclosure: This research received no grant from any funding agency in the public, commercial or notfor-profit sectors.

\section{References}

1. Bebbington P. The World Health Report 2001. Soc Psychiatry Psychiatr Epidemiol 2001;36:473-4

2. Mallika V, Goswami B, Rajappa M. Atherosclerosis pathophysiology and the role of novel risk factors: a clinicobiochemical perspective. Angiology 2007;58:513-22

3. Théroux P, Ouimet $\mathrm{H}, \mathrm{McCans} \mathrm{J}$, et al. Aspirin, heparin, or both to treat acute unstable angina. N Engl J Med 1988;319:1105-11.

4. Risk of myocardial infarction and death during treatment with low dose aspirin and intravenous heparin in men with unstable coronary artery disease. The RISC Group. Lancet 1990;336:827-30.

5. Lewis HD Jr, Davis JW, Archibald DG, et al. Protective effects of aspirin against acute myocardial infarction and death in men with unstable angina. Results of a Veterans Administration Cooperative Study. N Engl J Med 1983;309:396-403

6. Bertrand ME, Simoons ML, Fox KA, et al. Management of acute coronary syndromes in patients presenting without persistent ST-segment elevation. Eur Heart J 2002;23:1809-40.

7. Konkle BA, Schafer Al. Hemostasis, thrombosis, fibrinolysis, and cardiovascular disease. In Zipes DP, Libby P, Bonow RO, Braunwald E, editors. Braunwald's Heart Disease. 7th ed.Philadelphia: Saunders; 2005. p. 2067-92.

8. Angiolillo DJ, Guzman LA, Bass TA. Current antiplatelet therapies: benefits and limitations. Am Heart J 2008;156(2 Suppl):3-9.

9. Wiviott $\mathrm{SD}$, Braunwald E, McCabe $\mathrm{CH}$, et al. Prasugrel versus clopidogrel in patients with acute coronary syndromes. N Engl J Med. 2007;357:200115 .

10. Wallentin L, Becker RC, Budaj A, et al. Ticagrelor versus clopidogrel in patients with acute coronary syndromes. N Engl J Med 2009;361:1045-57.

11. Valgimigli M, Bueno H, Byrne RA, et al. 2017 ESC focused update on dual antiplatelet therapy in coronary artery disease developed in collaboration with EACTS: The Task Force for dual antiplatelet therapy in coronary artery disease of the European Society of Cardiology (ESC) and of the European Association for Cardio-Thoracic Surgery (EACTS). Eur Heart J 2018;39:213-60.

12. Sarafoff N, Martischnig A, Wealer J, et al. Triple therapy with aspirin, prasugrel, and vitamin $\mathrm{K}$ antagonists in patients with drug-eluting stent implantation and an indication for oral anticoagulation. J Am Coll Cardiol 2013;61:2060-6.

13. Dewilde WJ, Oirbans T, Verheugt FW, et al. Use of clopidogrel with or without aspirin in patients taking oral anticoagulant therapy and undergoing percutaneous coronary intervention: an open-label, randomised, controlled trial. Lancet 2013;381:1107-15. 
14. Feher G, Feher A, Pusch G, et al. Clinical importance of aspirin and clopidogrel resistance. World J Cardiol 2010;2:171-86.

15. Bonello L, Tantry US, Marcucci R, et al. Consensus and future directions on the definition of high on-treatment platelet reactivity to adenosine diphosphate. J Am Coll Cardiol 2010;56:919-33.

16. Tóth O, Calatzis A, Penz S, Losonczy H, Siess W. Multiple electrode aggregometry: a new device to measure platelet aggregation in whole blood. Thromb Haemost 2006;96:781-8.

17. Sibbing D, Braun S, Jawansky S, et al. Assessment of ADP-induced platelet aggregation with light transmission aggregometry and multiple electrode platelet aggregometry before and after clopidogrel treatment. Thromb Haemost 2008;99:121-6.

18. Mason PJ, Jacobs AK, Freedman JE. Aspirin resistance and atherothrombotic disease. J Am Coll Cardiol 2005;46:986-93.

19. Hankey GJ, Eikelboom JW. Aspirin resistance. Lancet 2006;367:606-17.

20. Nguyen TA, Diodati JG, Pharand C. Resistance to clopidogrel: a review of the evidence. J Am Coll Cardiol 2005;45:1157-64.

21. Chen WH, Lee PY, Ng W, Tse HF, Lau CP. Aspirin resistance is associated with a high incidence of myonecrosis after non-urgent percutaneous coronary intervention despite clopidogrel pretreatment. J Am Coll Cardiol 2004;43:1122-6.

22. Gurbel PA, Bliden KP, Hiatt BL, O'Connor CM. Clopidogrel for coronary stenting: response variability, drug resistance, and the effect of pretreatment platelet reactivity. Circulation 2003;107:2908-13.

23. Bhatt DL, Topol EJ. Scientific and therapeutic advances in antiplatelet therapy. Nat Rev Drug Discov 2003;2:15-28.

24. Gum PA, Kottke-Marchant K, Poggio ED, et al. Profile and prevalence of aspirin resistance in patients with cardiovascular disease. Am J Cardiol 2001;88:230-5

25. Helgason CM, Bolin KM, Hoff JA, et al. Development of aspirin resistance in persons with previous ischemic stroke. Stroke 1994;25:2331-6.

26. Hung J, Lam JY, Lacoste L, Letchacovski G. Cigarette smoking acutely increases platelet thrombus formation in patients with coronary artery disease taking aspirin. Circulation 1995;92:2432-6.

27. Matetzky S, Shenkman B, Guetta V, et al. Clopidogrel resistance is associated with increased risk of recurrent atherothrombotic events in patients with acute myocardial infarction. Circulation 2004;109:3171-5.

28. Furman MI, Benoit SE, Barnard MR, et al. Increased platelet reactivity and circulating monocyte-platelet aggregates in patients with stable coronary artery disease. J Am Coll Cardiol 1998;31:352-8.
29. Friend M, Vucenik I, Miller M. Research pointers: Platelet responsiveness to aspirin in patients with hyperlipidaemia. BMJ 2003;326:82-3.

30. Sahin DY, Koç M, Caylı M, et al. Kararlı koroner arter hastalığı olanlarda modifiye tromboelastogram yöntemi ile aspirin direnci sıklığ 1 ve klinik ve laboratuvar bulgularla ilişkisi [The frequency of aspirin resistance by a modified thrombelastography method and its relationship with clinical and laboratory parameters in patients with stable coronary artery disease]. Turk Kardiyol Dern Ars 2012;40:33-40.

31. Scott SA, Sangkuhl K, Stein CM, et al. Clinical Pharmacogenetics Implementation Consortium guidelines for CYP2C19 genotype and clopidogrel therapy: 2013 update. Clin Pharmacol Ther 2013;94:317-23.

32. Bundhun PK, Teeluck AR, Bhurtu A, Huang WQ. Is the concomitant use of clopidogrel and Proton Pump Inhibitors still associated with increased adverse cardiovascular outcomes following coronary angioplasty?: a systematic review and meta-analysis of recently published studies (2012 2016). BMC Cardiovasc Disord 2017;17:3.

33. Lau WC, Waskell LA, Watkins PB, et al. Atorvastatin reduces the ability of clopidogrel to inhibit platelet aggregation: a new drug-drug interaction. Circulation 2003;107:32-7.

34. Arbel Y, Birati EY, Finkelstein A, et al. Platelet inhibitory effect of clopidogrel in patients treated with omeprazole, pantoprazole, and famotidine: a prospective, randomized, crossover study. Clin Cardiol 2013;36:342-6.

35. Juurlink DN, Gomes T, Ko DT, et al. A population-based study of the drug interaction between proton pump inhibitors and clopidogrel. CMAJ 2009;180:713-8.

36. Gurbel PA, DiChiara J, Tantry US. Antiplatelet therapy after implantation of drug-eluting stents: duration, resistance, alternatives, and management of surgical patients. Am J Cardiol 2007;100:18M-25M.

37. Bonello-Palot N, Armero S, Paganelli F, et al. Relation of body mass index to high on-treatment platelet reactivity and of failed clopidogrel dose adjustment according to platelet reactivity monitoring in patients undergoing percutaneous coronary intervention. Am J Cardiol 2009;104:1511-5.

38. Feher G, Koltai K, Alkonyi B, et al. Clopidogrel resistance: role of body mass and concomitant medications. Int J Cardiol 2007;120:188-92.

39. Geisler T, Anders N, Paterok M, et al. Platelet response to clopidogrel is attenuated in diabetic patients undergoing coronary stent implantation. Diabetes Care 2007;30:372-4. 